\title{
Determination of serum vitamin D status of mothers and newborns and related outcomes
}

\author{
Ufuk Ayşe Kepkep ${ }^{1}$ and Ayla Gulden Pekcan ${ }^{2}$ \\ ${ }^{1}$ Nutrition and Dietetic Center, Gaziantep, Turkey and \\ ${ }^{2}$ Hasan Kalyoncu University Faculty of Health Sciences Department of Nutrition and Dietetics, Gaziantep, Turkey
}

\section{Abstract}

Vitamin D deficiency (VDD) has been associated with severe adverse health outcomes during pregnancy is increasingly recognised as a public health concern and maternal and infant VDD is closely associated. The aim of this study was to evaluate the magnitude of VDD and associated factors in pregnant women and newborns in the postpartum period. A cross-sectional study was carried out in a total of 66 pregnant women at $>37$ weeks of gestation and newborns at the Gaziantep University Faculty of Medicine, Department of Obstetrics and Gynecology in Gaziantep, Turkey. Demographic characteristics, 24-h dietary recalls, intake of food supplements were determined in pregnant women, maternal and newborn anthropometric measurements and serum (25-OHD) levels were assessed. Mean age $( \pm$ SD) of pregnant women was $28.8 \pm 6.9$ years. Although Turkey has "National Vitamin D Supplementation Programme for Pregnant Women" only 33.3\% of women had VD supplementation during pregnancy, not all in the recommended levels (1200 IU/day). Mean $( \pm \mathrm{SD})$ serum $25(\mathrm{OH}) \mathrm{D}$ levels in pregnant women and cord blood of newborns were $17.3 \pm 9.0 \mathrm{ng} / \mathrm{mL}$ [non-supplemented women (NSW): $16.5 \pm 7.9 \mathrm{ng} / \mathrm{mL}$; supplemented women $(\mathrm{SW}): 18.8 \pm 11.0 \mathrm{ng} / \mathrm{mL}$ ] and $16.6 \pm 9.9 \mathrm{ng} / \mathrm{mL}$ [newborns of non-supplemented women (NNSW): $13.9 \pm 8.7 \mathrm{ng} / \mathrm{mL}$ and newborns of supplemented women (NSW): $22.1 \pm 10.1 \mathrm{ng} /$ $\mathrm{mL}$ ], respectively. Vitamin D severe deficiency $(<10 \mathrm{ng} / \mathrm{dL})$ was noted in $22.7 \%$, deficiency $(11-19 \mathrm{ng} / \mathrm{mL}) 51.5 \%$, insufficiency $(20-29 \mathrm{ng} / \mathrm{mL}) 15.2 \%$ and sufficiency $(\geq 30 \mathrm{ng} / \mathrm{mL}) 10.6 \%$ of the women whereas severe deficiency, deficiency, insufficiency and sufficiency respectively, were determined in $33.3 \%, 39.5 \%, 13.6 \%$ and $13.6 \%$ of newborns (NNSW vs NSW, p =006, p < 0.05 ). Median serum VD levels of NSW were statistically higher than NNSW $(p=0.000, p<0.05)$. Out of total, 86.4\% of women were dressing traditionally covered, and had lower serum VD level $(p=0.049, p>0.05)$. SW had higher median body weight $(p=0.026)$ and body mass index (BMI) $(p=0.036)$ levels than NSW $(p<0.05)$. No statistically significant differences were found between anthropometric measurements of NNSW and NSW groups, although birth weights of NNSW and NSW groups were determined as $3005.1 \pm$ $456.1 \mathrm{~g}$ and $3153 \pm 422.5 \mathrm{~g}(\mathrm{p}>0.05)$, respectively. Maternal serum vitamin D levels strongly were correlated with newborn levels. Maternal vitamin D deficiency is a great problem and "National Vitamin D Supplementation Programme for Pregnant Women and Infants" should be effectively implemented and monitored. Also fortification programme should be a national policy.

\section{Conflict of Interest}

There is no conflict of interest. 